\title{
Genetic variation of resistance to mercury poisoning in steelhead (Oncorhynchus mykiss) alevins
}

\author{
JM Blanc ${ }^{1}$, JD McIntyre ${ }^{2}$ and RC Simon ${ }^{3}$ \\ ${ }^{1}$ INRA, Unité de Recherche en Hydrobiologie, B.P. 3, 64310 Saint-Pée-sur-Nivelle, France; 25702 Sugarloaf Street, Anacortes, WA 98221, \\ USA; ${ }^{3}$ PO Box 341, Beulah, WY 82712, USA
}

\begin{abstract}
Newly hatched steelhead alevins were obtained from the factorial breeding of 24 male and 10 female steelhead trout, Oncorhynchus mykiss. Each set of offspring were in a separate cell. They were tested for resistance to intoxication by methylmercuric chloride $\left(\mathrm{CH}_{3} \mathrm{HgCl}\right)$ in water at a nearly constant mercury concentration of $8 \mu \mathrm{gl}^{-1}$. High mortality ( $81 \%$ of the tested alevins) occurred within 2 weeks. Resistance to intoxication, as measured by the time to death, as well as by the survival rate, shared high paternal and maternal variation with negligible interaction. Heritability of time to death was $0.59 \pm 0.17$; heritability of survival (all-or-
\end{abstract}

none trait) was lower $(0.26+0.09)$. Mercury in dead alevins increased with time to death, exhibiting a large environmental variation and (comparatively) negligible genetic influence. At the end of the bioassay, the mercury content in survivors varied widely (3-21 $\mathrm{g} \mathrm{g} \mathrm{g}^{-1}$ wet weight). The content was greater than, but correlated with that of dead alevins from the same cells, and it showed little relation with survival rate. Thus, it seems that resistance to poisoning implies a tolerance to high levels of mercury rather than a limitation of its accumulation.

Heredity (2003) 91, 255-261. doi:10.1038/sj.hdy.6800336

Keywords: Oncorhynchus mykiss; fish; genetics; mercury; tolerance; toxicity

\section{Introduction}

Interest in environmental contamination by mercury as a potent threat to human health had developed by the 1960s, following the pollution of Minamata Bay (Japan) in 1953 and its drastic consequences for fishermen and fish consumers in that area (Clarkson, 1992). At that time, mercury compounds were released as byproducts of the chemical industry, antifouling treatments from pulp mills, or agricultural fungicides (Sorensen, 1991). Currently, pollution is under greater control, but mercury is still present in aquatic sediments where it is methylated by microorganisms (Clarkson, 1992), then transferred and accumulated in food chains (Jernelöv and Lann, 1971; Sorensen, 1991; Bowles et al, 2001). The highest concentrations are attained in edible tissues of long-lived predatory fishes, so that consumption of such fishes and fish products may become a human health hazard. Clarkson (1992) identified mercury contamination as a major problem in environmental health.

Mercury poisoning and retention in fish have been investigated in many studies (reviewed by Sorensen, 1991), but information is lacking about the genetic variability of fishes' tolerance of mercury. Such variability could allow fish populations to evolve, under the selective pressure caused by mercury, towards increased resistance, with or without an increase of the amount of

Correspondence: JM Blanc, INRA, Unité de Recherche en Hydrobiologie, B.P. 3, 64310 Saint-Pée-sur-Nivelle, France. E-mail: jmb@st-pee.inra.fr Received 25 March 2003 toxicant tolerated in the fish tissues prior to death. In other organisms (plants and invertebrates), metal-resistant strains have been found in contaminated areas, but the genetic determinism of these resistances has not been ascertained (Bryan, 1976). In the mosquitofish, Gambusia holbrooki, allozyme analyses suggested a selective effect of mercury at a few loci, particularly the glucosephosphate isomerase-2 locus (Diamond et al, 1989; Heagler et al, 1993; Mulvey et al, 1995; Tatara et al, 1999). We know of no overall measurement of genetic adaptative capabilities of fish for mercury.

We report the results of a study carried out in 1971 for a graduate degree (Blanc, 1973). Our purpose was to estimate the potential for genetic modification of steelhead, Oncorhynchus mykiss, populations through the selective action of methylmercury, which is the highly toxic, bioaccumulated form of the metal (Bryan, 1976; Clarkson, 1992). Our objective was to estimate the heritability (Falconer and Mackay, 1996) of resistance to methylmercury toxicity and to relate that resistance to the mercury accumulated in the fish. The bioassays were conducted on alevins because they are the development stage most susceptible to intoxication (Akiyama, 1970; Wobeser, 1975; McKim et al, 1976).

\section{Materials and methods}

Steelhead alevins produced in a factorial mating design were maintained for 2 weeks in a recirculating water system containing methylmercuric chloride $\left(\mathrm{CH}_{3} \mathrm{HgCl}\right)$ at a concentration approximating $8 \mu \mathrm{g}$ mercury $(\mathrm{Hg}) 1^{-1}$. 
We recorded the number of alevins that died each day, the number of survivors at the end of the bioassay, and the average mercury content in samples of dead and surviving alevins.

\section{Experimental animals}

The matings were accomplished in May 1971, with 10 female and 24 male steelhead obtained from a trap maintained and operated by Oregon Department of Fish and Wildlife on the North Santiam River. Gametes of each fish were placed into separate polyethylene bags, kept cool over ice in styrofoam coolers, and transported to Oregon State University (Corvallis, OR, USA). Within $8 \mathrm{~h}, 240$ matings were performed by fertilizing, with sperm from each male, 24 subsamples of eggs from each of the 10 females. The fertilized eggs were put into 240 separate cells in a Heath incubator provided with dechlorinated city water at $6.0 \pm 0.5^{\circ} \mathrm{C}$, as described by McIntyre and Blanc (1973b). Just before hatching, two samples of 20 eggs each were removed from each cell of the incubator and placed into separate cells, randomly allocated, in the bioassay apparatus. Hatching occurred in the following days (McIntyre and Blanc, 1973b) and the bioassay was initiated 2 days after hatching ended.

\section{Bioassay apparatus and method}

The apparatus was contained in a constant temperature room at $11^{\circ} \mathrm{C}$. It consisted of a series of four enameled troughs with interconnections to permit a closed water circuit. Dechlorinated city water was propelled by a small pump and a constant supply of air was injected into a reservoir within the system. The total volume of water was 2131 and the flow was maintained between 500 and $1000 \mathrm{ml}$ per minute. Each trough contained 120 cylindrical cells made from $50 \mathrm{~mm}$ diameter PVC pipe that had been cut to a length of $50 \mathrm{~mm}$. These cells were cemented together and, at the bottom, to a continuous plastic screen. The cells and screen were supported by glass rods, $10 \mathrm{~mm}$ above the bottom of the trough, so that the water could freely irrigate each cell.

At the onset of the bioassay, $\mathrm{CH}_{3} \mathrm{HgCl}\left(100 \mathrm{mg} \mathrm{Hgl}^{-1}\right.$ aqueous solution) was poured into the system, but subsequent analyses showed diminishing mercury levels. It was therefore necessary to add more $\mathrm{CH}_{3} \mathrm{HgCl}$ solution at irregular intervals to maintain the concentration at approximately $8 \mu \mathrm{g} \mathrm{Hg}^{-1}$ (daily checks showed that it fluctuated between 6 and $10 \mu \mathrm{g} \mathrm{Hgl}^{-1}$ ). Mercury depletion probably arose from a combination of fish absorption, elimination with filtered metabolic wastes, and adsorption on the container and cell walls. Alevins began dying on day 2 after the onset of the assay, mortality increased rapidly until day 5, and subsequently decreased progressively to a negligible level by day 10 . On day 14 , the experiment was concluded.

\section{Counts and analyses}

During the bioassay, dead alevins in every cell were counted daily, placed into plastic bags and stored in a freezer. When the assay was concluded, the number of survivors in every cell was recorded. From each of the 62 cells where survival was at least 50\%, 10 alevins were sampled and frozen. Subsequently, the frozen material was analyzed for total mercury content. Each sample was thawed, weighed, digested at about $50^{\circ} \mathrm{C}$ using nitric and sulphuric acids, oxidized with potassium permanganate and hydrogen peroxide and analyzed by flameless atomic absorption spectrophotometry (Uthe et al, 1970). Tests showed that this method recovered about $90 \%$ of the total mercury with a relative error less than $10 \%$. Also, the presence of some residual water in the fry samples was a minor source of error, which could not be evaluated.

\section{Statistical methods}

From the counts of dead alevins and survivors in every experimental cell, two variables were computed:

- the survival rate $S$ (in \%) in the cell;

- the survival time $T$ (time to death, in days) of every individual that died during the assay period.

From the subsequent analyses, two other variables were obtained:

- the mean mercury content $M\left(\mu g g^{-1}\right)$ of the dead alevins from every cell;

- the mean mercury content $M_{\mathrm{S}}\left(\mu \mathrm{g} \mathrm{g}^{-1}\right)$ of the survivors, only from the cells where the survival rate was at least $50 \%$.

There were few missing data, the impact of which was negligible on the statistical treatment (unweighted analysis of sib-group means): one cell was destroyed accidentally during the bioassay, another had $100 \%$ survival (no $T$ nor $M$ data), and one mercury $\left(M_{\mathrm{S}}\right)$ analysis failed.

The variables were transformed to stabilize variance (Snedecor and Cochran, 1967): the angular transformation, $y=10$ arcsine $\left(x^{1 / 2}\right)$, was used on survival rate; the logarithmic transformation, $y=10 \log _{10}(x)$, was used on time to death and mercury contents. The variance in the transformed variables was analyzed according to the model:

$$
Y_{\mathrm{ijk}}=\mu+\mathrm{Sr}_{\mathrm{i}}+\mathrm{Dm}_{\mathrm{j}}+\mathrm{SrDm}_{\mathrm{ij}}+R_{\mathrm{ijk}}+E_{\mathrm{ijk}}
$$

where $Y_{\mathrm{ijk}}$ is the transformed variable in the replicate $\mathrm{k}$ of the progeny from the sire $i$ and the dam $j, \mu$ is the overall mean, $\mathrm{Sr}_{\mathrm{i}}$ the additive genetic effect of sire $\mathrm{i}, \mathrm{Dm}_{\mathrm{j}}$ the additive genetic and maternal effect of dam j, $\mathrm{SrDm}_{\mathrm{ij}}$ the effect of genetic interaction between sire $i$ and dam $j, R_{i j k}$ the environmental effect (replicated cells in the apparatus), and $E_{\mathrm{ijk}}$ the error caused by sampling (individual variation) and measurement error.

$E_{\mathrm{ijk}}$ could be estimated only for variables $T$ (actual measurement of individual variation within cells) and $S$ (binomial error).

The components of variance were computed according to Becker (1984) from the mean squares of the analysis of variance. Heritabilities for $S$ and $T$ traits were estimated from the paternal variance $\left(V_{\mathrm{Sr}}\right)$, as: $h^{2}=4 V_{\mathrm{Sr}} / V_{\mathrm{P}} V_{\mathrm{P}}$ being the individual phenotypic variance. For the time to death, $V_{\mathrm{P}}$ was estimated as the total of between-cell variance components and individual variance within cells (Becker, 1984). For the survival (all-or-none trait), $V_{\mathrm{P}}$ was estimated as the variance of the binomial distribution, according to Robertson and Lerner (1948). Heritability was also estimated for the survival liability (underlying character with continuous distribution) according to the threshold model (Roff, 1997): heritability was computed on the binomial scale without transformation, then corrected by the factor $p(1-p) / z^{2}, p$ being 
the mean survival frequency and $z$ the ordinate on the standardized normal curve corresponding to a probability $p$.

Structural correlations (attributable to the sources of variation of the model) were computed from the mean cross products of variables $S$ and $T, T$ and $M$, and $S$ and $M$, according to Becker (1984). Total and partial regressions of $M$ on $T$ and of $S$ on $M$ were obtained according to Snedecor and Cochran (1967). Mercury in the survivors $\left(M_{\mathrm{S}}\right)$ was only related to the $\mathrm{M}$ and $\mathrm{S}$ values of the corresponding cells, since the factorial model could not be used.

\section{Results}

Time to death and survival

Approximately $81 \%$ of the alevin population (7635 out of 9441) died between days 2 and 14 of the bioassay (Figure 1). The distribution of time to death was approximately log-normal, so the logarithmic transformation was efficient for this variable. The median lethal time was estimated as 5.3 days. In contrast, the survival rate distribution among the 479 experimental cells was strongly skewed, and 176 cells had no survivors. The angular transformation of these data therefore improved the distribution only modestly. The survival rate and the mean time to death were related to each other (Figure 2; correlation of transformed variables is 0.77 ).

Survival rate and time to death (Table 1) showed strong parental effects, with negligible interaction. In either trait, the dam component of variance exceeded slightly, but not significantly, that of sires, indicating little or no maternal effect (through egg quality) on resistance to mercury. Heritability estimates were 0.26 (with SE 0.09) for survival, and 0.59 (with SE 0.17) for time to death. The genetic correlation between the two traits, as estimated from the sire variation, was high $(0.97 \pm 0.03)$, while the environmental correlation, estimated from replicated cells, was lower (Table 1). The two traits, therefore, similarly reflected the genetics of resistance to mercury intoxication, even though survival had a lower heritability due to larger individual variance (caused by the binomial nature of the trait). The threshold model (Roff, 1997) provided an estimate of heritability for the survival liability of 0.32 (with SE 0.12), slightly superior

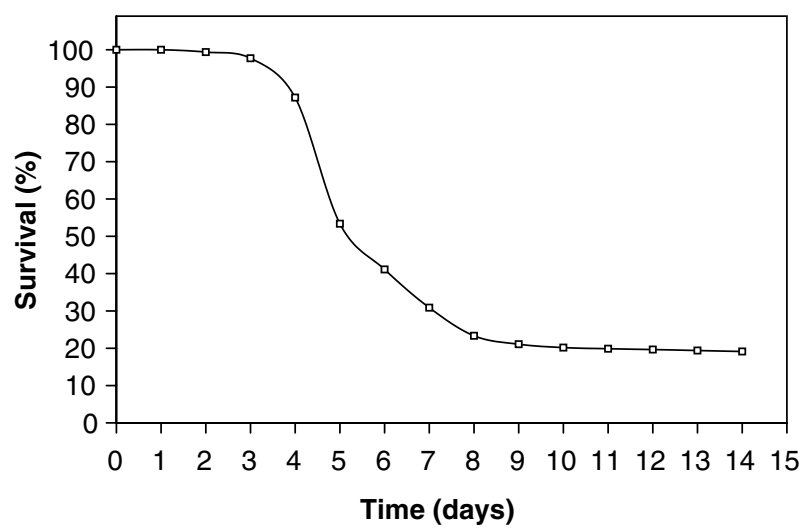

Figure 1 Evolution of survival in the experimental fry population submitted to intoxication with $\mathrm{CH}_{3} \mathrm{HgCl}$.

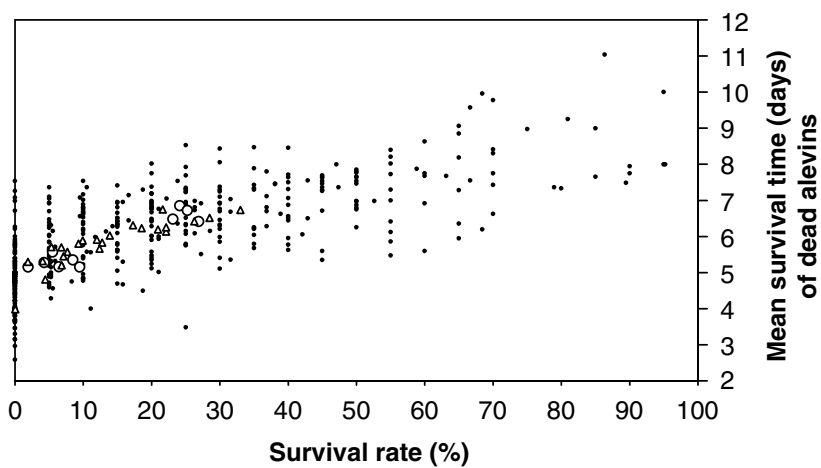

Figure 2 Relationship of time to death to survival rate among experimental cells (black dots), and means of paternal (triangles) and maternal (circles) progenies.

to that obtained with the angular-transformed survival rates.

\section{Mercury uptake}

The mean mercury content of dead alevins had a wide range of variation among cells (from 0.6 to $17.1 \mu \mathrm{g} \mathrm{g}^{-1}$ ) and was related to the corresponding mean time to death (Figure 3). The relation between the logarithms of these two variables was $r=0.62$. The variance of transformed mercury content (Table 1) was caused almost totally by the environmental source of variation (between replicates). Consequently, the analysis failed to show a significant effect of sires. Therefore, we attributed the existence of a significant mean square due to dams (although not significantly superior to that of sires) to small maternal effects rather than additive genetic effects. Heritability could not be estimated, for lack of measurements on individuals.

Comparing the correlation between mercury content and time to death or survival rate (Table 1) showed that the correlation among replicates was higher with time to death. This supported the hypothesis that a longer survival time allowed a higher mercury uptake, the latter being positively related to survival rate merely as a consequence of the relation between survival time and survival rate. Indeed, a multiple regression analysis (Table 2) showed that the regression of mercury content on time to death was about the same whether survival was fixed (partial regression) or not (total regression). In contrast, the positive relation between survival rate and mercury content was not significant or even negative when time to death was kept constant. Although negative partial regression was significant at the environmental level only, it indicated that, to some extent, greater survival could be the consequence of a slower rate of mercury uptake.

The mean mercury content in samples of surviving alevins at the end of the assay varied from 2.7 to $21.2 \mu \mathrm{g} \mathrm{g}^{-1}$, with a mean of $12.3 \mu \mathrm{gg}^{-1}$ (Figure 3). Mercury in survivors within a cell was always greater than that for dead alevins from the same cells (Figure 4). The correlation between the log-transformed variables was 0.96. Furthermore, the difference in mercury content between dead and living alevins was inversely related to the time to death in the former (correlation of transformed variables: -0.41$)$. Although analysis of variance was not feasible, examination of the data suggested that 
Table 1 Basic statistics of survival rate ( $S$, angular-transformed), time to death ( $T$, log-transformed), and mercury content of dead alevins ( $M$, log-transformed)

\begin{tabular}{|c|c|c|c|c|c|c|c|}
\hline & $\begin{array}{l}\text { Sources of } \\
\text { variation }\end{array}$ & Survival rate $(S)$ & & Time to death $(T)$ & & Mercury (M) & \\
\hline \multirow{4}{*}{ Mean squares and significance } & Sires & 41.19 & $* * * *$ & 4.98 & $* * * *$ & 11.83 & NS \\
\hline & Dams & 110.07 & $* * * *$ & 12.55 & $* * * *$ & 35.85 & $* * *$ \\
\hline & Interaction & 8.41 & NS & 0.56 & NS & 10.14 & NS \\
\hline & Replicates & 7.78 & $* * * *$ & 0.50 & $* * * *$ & 9.98 & - \\
\hline \multirow{6}{*}{$\begin{array}{l}\text { Components }(\%) \text { of variance } \\
( \pm \text { SE) }\end{array}$} & Sires & 15.5 & $( \pm 5.0)$ & 23.2 & $( \pm 6.4)$ & 0.8 & $( \pm 1.7)$ \\
\hline & Dams & 20.1 & $( \pm 7.6)$ & 26.2 & $( \pm 8.9)$ & 5.1 & $( \pm 2.9)$ \\
\hline & Interaction & 3.0 & $( \pm 5.2)$ & 3.4 & $( \pm 3.8)$ & 0.8 & $( \pm 6.4)$ \\
\hline & Replicates & 61.4 & $( \pm 8.4)$ & 47.2 & $( \pm 7.6)$ & $93.3^{\mathrm{a}}$ & $( \pm 6.7)$ \\
\hline & Total & 100.0 & & 100.0 & & 100.0 & \\
\hline & $\begin{array}{l}\text { Sources of } \\
\text { variation }\end{array}$ & $S$ and $T$ & & Tand $M$ & & $S$ and $M$ & \\
\hline \multirow[t]{4}{*}{ Mean cross products } & Sires & 13.01 & & 5.14 & & 12.06 & \\
\hline & Dams & 34.38 & & 15.89 & & 47.25 & \\
\hline & Interaction & 1.35 & & 1.47 & & 3.17 & \\
\hline & Replicates & 1.31 & & 1.59 & & 3.50 & \\
\hline \multirow{3}{*}{$\begin{array}{l}\text { Structural correlations } \\
( \pm S E)\end{array}$} & Sires & 0.97 & $( \pm 0.03)$ & Meaningless & & Meaningless & \\
\hline & Dams & 0.95 & $( \pm 0.04)$ & 0.82 & $( \pm 0.14)$ & 0.87 & $( \pm 0.14)$ \\
\hline & $\begin{array}{l}\text { Interaction } \\
\text { Replicates }\end{array}$ & $\begin{array}{c}\text { Meaningless }^{\mathrm{b}} \\
0.76\end{array}$ & $( \pm 0.04)$ & $\begin{array}{c}\text { Meaningless } \\
0.75\end{array}$ & $( \pm 0.03)$ & $\begin{array}{c}\text { Meanıngless } \\
0.43\end{array}$ & $( \pm 0.06)$ \\
\hline
\end{tabular}

Significance levels: ${ }^{* * *} P<0.001 ;{ }^{* * *} P<0.0001 ;$ NS, not significant $(P>0.05)$.

ancluding residual error.

${ }^{\mathrm{b} C}$ Correlations were considered as meaningless when their SE exceeded 0.5.

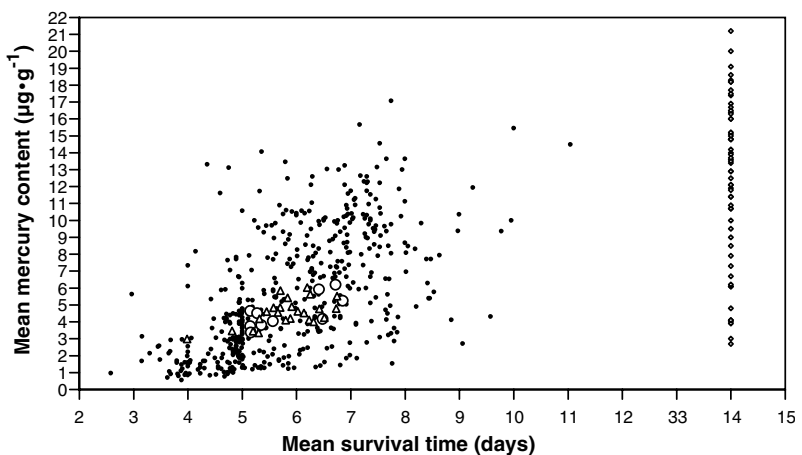

Figure 3 Relationship of mercury content of dead alevins to their survival time among experimental cells (black dots) and means of paternal (triangles) and maternal (circles) progenies, and distribution of mercury content of samples of survivors killed on day 14 (diamonds).

the environmental effect (within pairs of replicated cells) was much greater than the genetic effect. Finally, plotting survival rate against mercury content of survivors (Figure 5) failed to show any negative relationship. Rather, a positive correlation (0.74) was found within pairs of replicated cells.

\section{Discussion}

\section{Resistance to intoxication}

Insufficient space was available to include mercury-free control samples. However, the capacity of our apparatus to sustain the eggs and alevins alive despite the
Table 2 Regression coeffcients of mercury content of dead alevins ( $M, \log$-transformed) on time to death $(T, \log$-transformed), and survival rate $(S$, angular-transformed) on mercury $(M)$

\begin{tabular}{|c|c|c|c|c|c|c|}
\hline \multirow{3}{*}{$\begin{array}{l}\text { Sources of } \\
\text { variation } \\
\text { Sires }\end{array}$} & \multicolumn{6}{|c|}{ Regression of mercury $(\mathrm{M})$ on time to death $(\mathrm{T})$} \\
\hline & \multicolumn{3}{|c|}{ Total (on $\mathrm{T}$ alone) } & \multicolumn{3}{|c|}{ Partial (for survival constant) } \\
\hline & 1.03 & $( \pm 0.24)$ & $* * *$ & 1.55 & $( \pm 0.60)$ & * \\
\hline Dams & 1.27 & $( \pm 0.40)$ & $*$ & 0.59 & $( \pm 1.11)$ & NS \\
\hline Replicates & 3.19 & $( \pm 0.20)$ & $* * * *$ & 3.60 & $( \pm 0.27)$ & $* * * *$ \\
\hline \multirow{2}{*}{$\begin{array}{l}\text { Sources of } \\
\text { variation }\end{array}$} & \multicolumn{6}{|c|}{ Regression of survival rate (S) on mercury (M) } \\
\hline & \multicolumn{3}{|c|}{ Total (on M alone) } & \multicolumn{3}{|c|}{ Partial (for time to death constant) } \\
\hline Sires & 1.02 & $( \pm 0.33)$ & ** & -0.21 & $( \pm 0.22)$ & NS \\
\hline Dams & 1.32 & $( \pm 0.40)$ & * & 0.24 & $( \pm 0.36)$ & NS \\
\hline Replicates & 0.35 & $( \pm 0.05)$ & $* * * *$ & -0.14 & $( \pm 0.06)$ & $*$ \\
\hline
\end{tabular}

Significance levels: ${ }^{*} P<0.05 ;{ }^{* *} P<0.01 ;{ }^{* * *} P<0.001 ;{ }^{* * * *} P<0.0001$; NS, not significant $(P>0.05)$.

temperature elevation $\left(6-11^{\circ} \mathrm{C}\right)$ was demonstrated before mercury was introduced into the system. Furthermore, a smaller, subsequent experiment (eight sires $\times$ three dams in similar experimental conditions) included a control replicate for every sib-group, and clearly demonstrated that significant mortalities occurred only in the mercurytreated lots (McIntyre and Blanc, 1973a). Therefore, the survival rates and times recorded in the present experiment may be logically related to the alevins' tolerance to the toxicant. Nevertheless, synergistic effects 


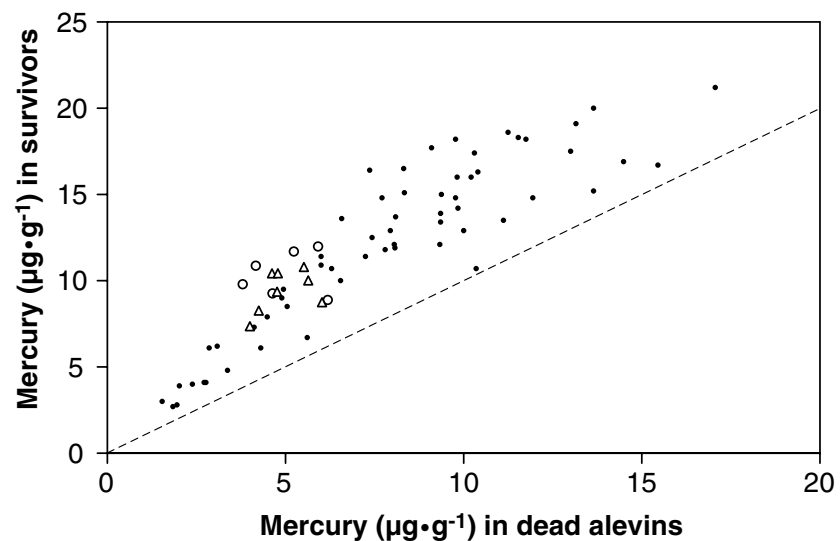

Figure 4 Relationship of the mercury content of survivors to that of dead alevins in the best surviving cells (black dots) and best surviving paternal (triangles) and maternal (circles) mean progenies. Dashed line: $y=x$.

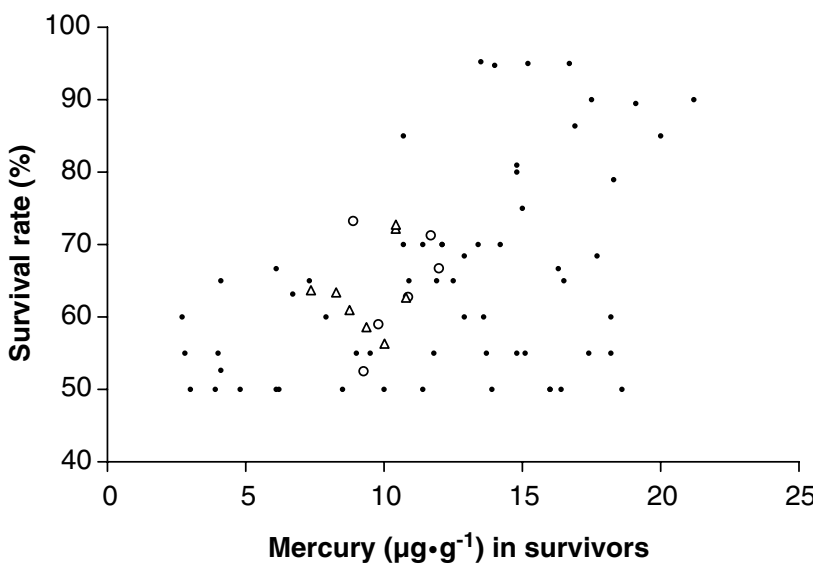

Figure 5 Relationship of survival rate to mercury content of survivors in the best surviving cells (black dots) and best surviving paternal (triangles) and maternal (circles) mean progenies.

of the toxicant with other aspects of water quality were possible and limit quantitative application of our results to other situations.

We found median time to death of 5.3 days for alevins exposed to $8 \mu \mathrm{g} \mathrm{Hgl}^{-1}$. Wobeser (1975) conducted a comparable bioassay (rainbow tested against $\mathrm{CH}_{3} \mathrm{HgCl}$ in water at $10^{\circ} \mathrm{C}$ ). He found no mortality at $10 \mu \mathrm{g} \mathrm{Hgl}^{-1}$ and estimated the 4-day median lethal concentration as $24 \mu \mathrm{g} \mathrm{Hgl}^{-1}$. His mercury concentrations were determined from the formulation of the test solutions, which were provided to fry in 11 flasks. Although these solutions were renewed at 24-h intervals, the amount of mercury actually available to the fry may have been less than expected, so that the fry resistance may have been somewhat overestimated. Other studies show that the level of resistance to mercury in water may vary considerably, according to the species (Sorensen, 1991), to the age of the fish (Akiyama, 1970; Wobeser, 1975; McKim et al, 1976), to the chemical form of mercury (Akiyama, 1970; MacLeod and Pessah, 1973), and to environmental conditions such as temperature, dissolved oxygen, and water hardness (Amend et al, 1969, MacLeod and Pessah, 1973). Comparison of results from different experiments requires caution. In the present study, the susceptibility of the very young fry as well as the treatment (methylmercuric chloride at $11^{\circ} \mathrm{C}$ ) contributed to the relatively low tolerance level observed.

The large variation among families in survival rate and time to death and the high genetic correlation between these two traits indicate that a fish population may have some capacity for adapting to mercury. In our experimental conditions (acute toxicity), the best indicator of biological resistance was time to death $\left(h^{2}=0.59 \pm 0.17\right)$. Survival was a much less precise variate, due to its binomial nature, but is the trait under selection $\left(h^{2}=0.26 \pm 0.09\right.$ or $0.32 \pm 0.12$ depending on the method of calculation), and therefore should be a better predictor of the population's response. Higher heritability estimates were initially computed from the same data (Blanc, 1973), but they are questionable, since they were based (1) on both paternal and maternal variations (and therefore could include some nongenetic maternal effects), and (2) on an estimator of selective value derived from survival rate through probit transformation and regression on time to death.

The heritability estimates obtained in this study are meaningful only to the extent that apparently resistant alevins can fully survive and contribute to the gene pool of the next generation. Although adults are likely to be less sensitive than alevins (Wobeser, 1975), they may be submitted to higher levels of intoxication by eating contaminated prey species (Jernelöv and Lann, 1971; Bryan, 1976; Phillips and Buhler, 1978). Furthermore, survivors may suffer from secondary growth and reproductive disorders, and transfer considerable amounts of mercury to their progeny (McKim et al, 1976). The present study was restricted to the fry stage. It was also concerned about acute toxicity only, while mercury levels actually encountered in natural environments are much lower. However, natural selection might also modify fish populations confronted with sublethal mercury concentrations, if the induced effects on growth and reproduction were submitted to similar genetic influences. Therefore, long-term studies are necessary to understand the selective effects of mercury throughout the entire life cycle of the fish.

\section{Mercury uptake}

The evidence of an important genetic contribution to mercury resistance raises questions concerning the physiological mechanisms through which this contribution acts. It may be the result of factors preventing the accumulation of toxicant in the body, or an increased tolerance in the tissues. Our analyses show that high concentrations may be found in surviving alevins (3$21 \mu \mathrm{gg}^{-1}$, Figure 3). The mean value of $12.3 \mu \mathrm{gg}^{-1}$ amounts to a concentration factor (concentration in fish/concentration in water) of about 1500. Even higher estimates were reported by Hannerz (1968) and McKim et al (1976). In brook trout (Salvelinus fontinalis) exposed for $16-28$ weeks to $\mathrm{CH}_{3} \mathrm{HgCl}$ at a concentration of $2.9 \mu \mathrm{g} \mathrm{Hgl}^{-1}$, McKim et al (1976) obtained an average concentration of $23.5 \mu \mathrm{g} \mathrm{g}^{-1}$, which was similar to that $\left(20 \mu \mathrm{g} \mathrm{g}^{-1}\right)$ of the fishes from the polluted Minamata Bay (Japan). 
Mercury accumulates at higher concentrations in organs such as the gills, the liver, the spleen, and the kidneys, which account for a relatively small part of the total body weight (Hannerz, 1968; Rucker and Amend, 1969; Giblin and Massaro, 1973). Therefore, the average mercury concentration in the whole fish is probably not a good indicator of the degree of illness. Unfortunately, alevins were too small to allow measurement of mercury concentration in any particular tissue.

The relationship of mercury in the dead alevins $(M)$ to their survival time $(T)$ is not informative, since the time to death directly influences the mercury concentration whatever the actual cause of death. Our results are in line with the regression equation computed by Phillips and Buhler (1978), who found the mercury accumulation rate $\left(\mu \mathrm{g} \mathrm{Hg} \mathrm{g}^{-1} \mathrm{day}^{-1}\right)$ to be $y=0.084 x, x$ being the concentration in water $\left(\mu \mathrm{g} \mathrm{Hgl}^{-1}\right)$; this leads to $M=0.67 \mathrm{~T}$ in our experiment, which fits reasonably well to the diagram in Figure 3. Rather, it is surprising that mortality ceased almost completely after day 10 (Figure 1), despite the fact that mercury apparently continued to accumulate in fish (since it was higher in survivors, Figure 3). This might indicate a decrease of alevins' sensitivity at that stage (end of vitelline resorption). However, this assertion assumes that dying fry accumulated mercury at the same rate as did healthy ones. If, as mentioned above, resistance was partly the result of physiological barriers preventing the accumulation of toxicant, then survivors should have shown lower mercury levels, which is not the case. On the contrary, it is possible that healthier alevins were more active and enhanced water exchange, as well as a higher metabolic rate causing them to absorb more mercury (Rodgers and Beamish, 1981). This would explain the higher content in survivors without presupposing a sustained accumulation of mercury after day 10. End of mortality could therefore have resulted from the onset of a balance between mercury contents in fish and in surrounding water.

Another surprising point is the relative importance of the replicate effect on the variation of mercury concentration. It was not caused by errors in the mercury analyses, since mercury in dead and surviving alevins from the same cells were highly correlated. Rather, it may be related to variations of the water flow among the cells of the experimental apparatus (some cases of concordance with the apparatus design were even observed). This brings a hypothetical source of positive correlation between mercury and survival, since other factors could vary with the water flow and particularly the quantity of available oxygen. Indeed, the gills experience the greatest damage from methylmercury, so the fish die mainly from suffocation (Amend et al, 1969, Akiyama, 1970; Olson et al, 1973). Oxygen might therefore have become a limiting factor, in which case survival would have increased in the well-irrigated cells in spite of an increase in the accumulation of mercury. It is also possible that, as mentioned above, healthier alevins were more active and absorbed more mercury. Obviously, there are several questions that the present study does not answer, mainly because it lacks data on the dynamics of mercury accumulation in surviving fry. Further research is needed concerning the genetic relationship between mercury uptake and survival. We can only state that, although a slower rate of mercury uptake should logically result in greater survival, our data did not confirm such a relation.

Studies on the histopathological effects of mercury (Sorensen, 1991) show that it binds sulfhydryl groups that are contained in most proteins, and therefore damages cellular constituents, affecting particularly the permeability of plasma membranes. This induces deleterious effects in most organs, including the nervous system. In fish, the acute toxic action is primarily exerted on the secondary lamellae of gill epithelium (Wobeser, 1975), and is either related to inhibition of the $\mathrm{Na}^{+} / \mathrm{K}^{+}-$ ATPase (at lethal concentrations of mercury), or (more generally) to an increase of the cell membranes permeability for water (Lock et al, 1981). This causes hyperplasia and necrosis of the cells, and therefore affects the osmoregulatory and respiratory functions of the gills (Amend et al, 1969; Wobeser, 1975). Several mechanisms of resistance may have interferred in this study, causing the observed genetic differences in survival, independently from mercury intake. For instance (1), protein composition or structure may modify the sensitivity of cell membranes to mercury. This would be a general mechanism, not only preventing acute toxicity in gills, but also other, sublethal, physiological disorders. Resistance may also involve (2) metabolic processes enhancing transport of mercury out of the gills, and storage in other organs (liver). And (3), increase of respiratory movements and blood circulation may partly compensate for gill damage, thus preventing short-term death, but not secondary effects. Elucidation of such mechanisms is beyond the reach of this study and would require physiological experiments specially designed for that purpose.

The relative amount of mercury concentrated in the edible tissues is an important consideration because of consequences to human health. Studies on the mercury distribution in fish (Hannerz, 1968, Rucker and Amend, 1969, Giblin and Massaro, 1973) show that the muscular concentration does not differ much from the whole body average (muscles account for about $55 \%$ of the body weight). However, even when intake of mercury is suspended, skeletal muscles appear to function as a reservoir for methylmercury. Elimination of methylmercury is extremely slow, with a half-retention time of more than 200 days (Giblin and Massaro, 1973, Ruohtula and Miettinen, 1975). Therefore, the relationship between adaptive tolerance and tissue levels needs further study because of the potential environmental health hazards associated with mercury.

\section{Acknowledgements}

The experiment reported here was carried out in the facilities of the Department of Fisheries and Wildlife, Oregon State University, Corvallis, Oregon, where the first author was accepted in 1970 as a foreign student and research assistant. The Fish Commission of Oregon (now part of Oregon Department of Fish and Wildlife) kindly provided the spawners for this experiment. We are indebted to B McPherson (Oregon Department of Fish and Wildlife) for his important advice about the techniques and interpretation of mercury analyses, to KE Rowe (Oregon State University) for his helpful suggestions, and to A Gharrett (University of AlaskaJuneau), R Reisenbichler (US Geological Survey, Western 
Fisheries Research Center, Seattle, Washington), and Heredity reviewers for their useful comments on this manuscript.

\section{References}

Akiyama A (1970). Acute toxicity of two organic mercury compounds to the teleost, Oryzias latipes, in different stages of development. Bull Jap Soc Sci Fish 36: 563-570.

Amend DF, Yasutake WT, Morgan R (1969). Some factors influencing susceptibility of rainbow trout to the acute toxicity of an ethyl mercury phosphate formulation (Timsan). Trans Am Fish Soc 98: 19-425.

Becker WA (1984). Manual of Quantitative Genetics, 4th edn. Academic Enterprises: Pullman.

Blanc JM (1973). Genetic Aspects of Resistance to Mercury Poisoning in Steelhead Trout (Salmo gairdneri). MSc thesis, Oregon State University.

Bowles KC, Apte SC, Maher WA, Kawei M, Smith R (2001). Bioaccumulation and biomagnification of mercury in Lake Murray, Papua New Guinea. Can J Fish Aquat Sci 58: 888-897.

Bryan GW (1976). Some aspects of heavy metal tolerance in aquatic organisms. In: Lockwood APM (ed) Effects of Pollutants on Aquatic Organisms, Cambridge University Press: Cambridge. pp 7-34.

Clarkson TW (1992). Mercury: major issues in environmental health. Environ Health Perspect 100: 31-38.

Diamond SA, Newman MC, Mulvey M, Dixon PM, Martinson D (1989). Allozyme genotype and time to death of mosquitofish, Gambusia affinis (Baird and Girard), during acute exposure to inorganic mercury. Environ Toxicol Chem 8: 613-622.

Falconer DS, Mackay TFC. (1996). Introduction to Quantitative Genetics, 4th edn. Longman: Edinburgh.

Giblin FJ, Massaro EJ (1973). Pharmacodynamics of methyl mercury in the rainbow trout (Salmo gairdneri): tissue uptake, distribution and excretion. Toxicol Appl Pharmacol 24: 81-91.

Hannerz L (1968). Experimental investigations on the accumulation of mercury in water organisms. Rep Inst Fresh Res Drottningholm 48: 120-176.

Heagler MG, Newman MC, Mulvey M, Dixon PM (1993). Allozyme genotype in mosquitofish, Gambusia holbrooki, during mercury exposure: temporal stability, concentration effects and field verification. Environ Toxicol Chem 12: 385-395.

Jernelöv A, Lann H (1971). Mercury accumulation in food chains. Oikos 22: 403-406.

Lock RAC, Cruijsen PMJM, van Overbeeke AP (1981). Effects of mercuric chloride and methylmercuric chloride on the osmoregulatory function of the gills in rainbow trout, Salmo gairdneri Richardson. Comp Biochem Physiol 68C: 151-159.

MacLeod JC, Pessah E (1973). Temperature effects on mercury accumulation, toxicity, and metabolic rate in rainbow trout (Salmo gairdneri). J Fish Res Board Can 30: 485-492.
McIntyre JD, Blanc JM (1973a). Genetic aspects of mercury toxicity for steelhead trout (Salmo gairdneri): a progress report. Proc Western Assoc State Fish Game Commis 1972: 575-578.

McIntyre JD, Blanc JM (1973b). A genetic analysis of hatching time in steelhead trout (Salmo gairdneri). J Fish Res Board Can 30: 137-139.

McKim JM, Olson GF, Holcombe GW, Hunt EP (1976). Longterm effects of methylmercuric chloride on three generations of brook trout (Salvelinus fontinalis): toxicity, accumulation, distribution, and elimination. I Fish Res Board Can 33 2726-2739.

Mulvey M, Newman MC, Chazal A, Keklak MM, Heagler MG, Hales Jr LS (1995). Genetic and demographic responses of mosquitofish (Gambusia holbrooki Girard 1859) populations stressed by mercury. Environ Toxicol Chem 14: 1411-1418.

Olson KR, Bergman HL, Fromm PO (1973). Uptake of methyl mercuric chloride by trout: a study of uptake pathways into the whole animal and uptake by erythrocytes in vitro. J Fish Res Board Can 30: 1293-1299.

Phillips GR, Buhler DR (1978). The relative contributions of methylmercury from food or water to rainbow trout (Salmo gairdneri) in a controlled laboratory environment. Trans Am Fish Soc 107: 853-861.

Robertson A, Lerner IM (1948). The heritability of all-or-none traits: viability in poultry. Genetics 34: 395-411.

Rodgers DW, Beamish FWH (1981). Uptake of waterborne methylmercury by rainbow trout (Salmo gairdneri) in relation to oxygen consumption and methylmercury concentration. Can J Fish Aquat Sci 38: 1309-1315.

Roff DA (1997). Evolutionary Quantitative Genetics. Chapman \& Hall: New York.

Rucker RR, Amend DF (1969). Absorption and retention of organic mercurials by rainbow trout and chinook and sockeye salmon. Prog Fish Cult 31: 197-201.

Ruohtula M, Miettinen JK (1975). Retention and excretion of ${ }^{203} \mathrm{Hg}$-labelled methylmercury in rainbow trout. Oikos 26: 385-390.

Snedecor GW, Cochran WG (1967). Statistical Methods, 6th edn. Iowa State University Press: Ames

Sorensen EMB. (1991). Metal Poisoning in Fish. CRC Press: Boca Raton.

Tatara CP, Mulvey M, Newman MC (1999). Genetic and demographic responses of mosquitofish (Gambusia holbrooki) populations exposed to mercury for multiple generations. Environ Toxicol Chem 18: 2840-2845.

Uthe JF, Armstrong FAJ, Stainton MP (1970). Mercury determination in fish samples by wet digestion and flameless atomic absorption spectrophotometry. J Fish Res Board Can 27: 805-811.

Wobeser G (1975). Acute toxicity of methyl mercury chloride and mercuric chloride for rainbow trout (Salmo gairdneri) fry and fingerlings. J Fish Res Board Can 32: 2005-2013. 